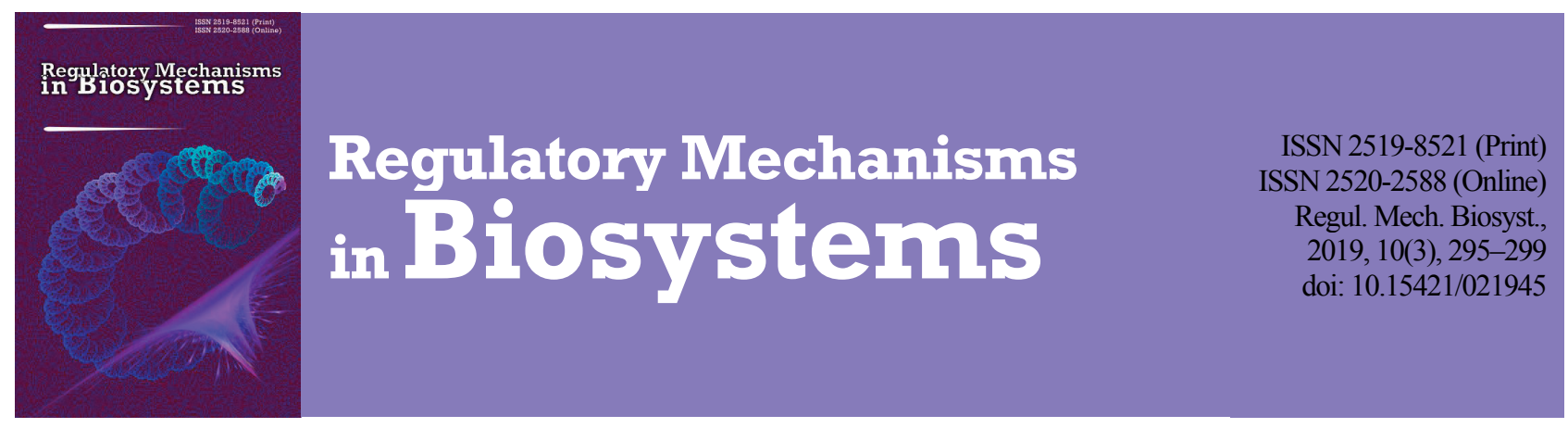

\title{
Influence of pathogenetic factors of type 2 diabetes on activation of PI3K/AkT/mTOR pathway and on the development of endometrial and breast cancer
}

\author{
T. S. Vatseba \\ Ivano-Frankivsk National Medical University, Ivano-Frankivsk, Ukraine
}

Article info

Received 12.07.2019

Received in revised form 17.08.2019

Accepted 18.08.2019

Ivano-Frankivsk National Medical University,

Halytska st., 2, Ivano-

Frankivsk, 76018, Ukraine.

Tel.: +38-050-974-30-07.

E-mail:

tamara.vatseba@gmail.com

\begin{abstract}
Vatseba, T. S. (2019). Influence of pathogenetic factors of type 2 diabetes on activation of PI3K/AkT/mTOR pathway and on the development of endometrial and breast cancer. Regulatory Mechanisms in Biosystems, 10(3), 295-299. doi:10.15421/021945

Type 2 diabetes (T2D), which is an epidemic of the 20th century, increases mortality, caused not only by cardiovascular diseases but also cancer. Pathogenetic factors of T2D lead to dysfunction of intracellular regulatory systems, particularly of PI3K/Akt/mTOR signaling pathway, which is involved in development of breast and endometrial cancer. During the study, the activation of this pathway by cancer and T2D was examined by determining the content of phosphorylated PRAS40 and p70S6K1. We studied the link between these kinases and pathogenetic factors of T2D. 65 women were examined. Patients were divided into four groups: I healthy, II - women with T2D, III - women with cancer without diabetes, IV - women with cancer and T2D. Level of HbA1c was determined by the ion-exchange chromatography. Levels of insulin, IGF-1, phospho-PRAS40, phospho-p70S6K1 were determined in PBMCs by immune-enzymatic methods. According to research results, significant hyperinsulinemia was detected in both groups with T2D. The highest level of insulin was in group II. A significantly higher level of IGF-1 was found only in patients with cancer of group III. The content of phospho-PRAS40 and phospho-p70S6K1 was higher in women with T2D of group II and in women with cancer of group III. Patients in group IV with combination of cancer and T2D had a lower level of phospho-PRAS40 in comparison to other groups. Phospho-PRAS40 in group II correlates with insulin, IGF-1 and HbAlc; in groups III and IV only with BMI. Phospho-p70S6K1 correlates with IGF-1 and with HbA1c in group II. Pathogenetic factors of T2D activate the signal path $\mathrm{PI} 3 \mathrm{~K} / \mathrm{Akt} / \mathrm{mTOR}$, which is involved in the regulation of oncogenesis and metabolism. Phosphorylation of PRAS40 and p70S6K1 reflects the activation of P13K/Akt/mTOR pathway in women with T2D. Increased levels the phospho-PRAS40 and phosphop70S6K1 can be used as early markers of oncogenesis in women with T2D.
\end{abstract}

Keywords: insulin; IGF-1; hyperglycemia; oncogenesis; intracellular regulatory systems.

\section{Introduction}

Patients with T2D have an increased risk of certain localized cancers, including breast, endometrial (Joung et al., 2015), pancreas (Beg et al., 2014), prostate (Gang et al., 2015), liver and intestine cancer (Harding et al., 2015; Zhu et al., 2017; Vatseba \& Sokolova, 2018). Considering the prevalence of diabetes mellitus (DM) nowadays, the impressive increase in the incidence of oncological diseases could well be related to this background pathology. A scientific discussion about cancer as a possible consequence of DM or DM as a paraneoplastic syndrome is being conducted. Both hypotheses may be correct.

Breast and endometrial cancer are some of the most common types of cancer in women in the postmenopausal period (Lykholat et al., 2016). Among the mechanisms of the association of this cancer and T2D are the effects of hyperinsulinemia, obesity, cytokine imbalance and hyperglycemia (García-Jiménez et al., 2015; Hendriks et al., 2018).

Excessive insulin causes mutational effects through insulin receptors (IR) and insulin-like growth factor receptors (IGF-R), contributing to the malignant transformation of healthy cells by stimulating mitotic processes and suppressing apoptosis (Ferroni et al., 2016). Obesity in patients with T2D leads to estrogen-dependent endometrial and breast cancer due to hyperestrogenism, which is caused by excessive peripheral aromatisation of androgens in adipose tissue (Joung et al., 2015). Cytokine imbalance, caused by obesity, is an important factor of oncogenesis in patients with T2D. Pro-cancer effects of tumour necrosis factor$\alpha$ (TNF- $\alpha$ ), interleukin-6 (IL-6) and leptin, which contribute to hyperes- trogenemia and growth of estrogen-dependent tumour cells, have been proved. Leptin receptors (Lep-R) in mammary gland cells are considered as a marker of an unfavourable disease prognosis (Pan et al., 2018). Adiponectin, on the other hand, has insulin-sensitive and oncoprotective properties (Gu et al., 2018). Hyperglycemia is also a potent factor for oncogenesis in patients with diabetes. Glucose causes not only endocrine (insulin secretion), but also progenotoxic (generation of reactive oxygen species (ROS)) effects, which are associated with mitochondrial damage. Hyperglycemia enhances cell proliferation (Chang et al., 2016).

It is proved that these pathogenetic factors of T2D cause changes on the level of intracellular regulatory systems. PI3K/AkT/mTOR is one of the most important signalling pathways in the cell. Under normal conditions it provides its livelihood, regulates the synthesis of proteins and lipids, suppresses gluconeogenesis and lipolysis and also affects insulin sensitivity. However by severe dysmetabolism, excessive stimulation of protein kinases of this system causes oncogenic effects. Activators of this signalling system are growth factors, amino acid deficiency, hypoxia and oxidative stress (Saxton \& Sabatini, 2017).

The role of PI3K/AkT/mTOR in breast and endometrial cancer has been proved in a lot of research (Chen et al., 2014; Guerrero-Zotano et al., 2016; Hare \& Harvey, 2017). Today the study of influence of pathogenetic factors of T2D on the functioning of this signalling system continues. Under the influence of excess insulin and IGF-1 phosphoinositide 3-kinase (PI3K) the serine/threonine protein kinase cascade is activated, in particular, phosphoinositide-dependent kinase-1 (PDK-1), the substrate of which is Akt from the family of protein kinases B. Akt 
through phosphorylation processes affects the activity of mTOR (mammalian target of rapamycin), which is a key coordinator of the adaptive mechanisms of cell survival. mTOR includes two complexes: mTORC1 and mTORC2. Raptor and PRAS40 (proline-rich Akt substrate of $40 \mathrm{kDa}$ ) are specific for $\mathrm{mTORC} 1$, and for $\mathrm{mTORC} 2$ - rictor and $\mathrm{mSin} 1$. These complexes interact with different substrates and initiate various signalling pathways. The phosphorylation of PRAS40 leads to the dissociation of PRAS40 with raptor in the mTORC1 complex, which promotes activation of mTOR. Increased levels of phospho-PRAS40 were revealled in several types of tumours, including tumours of the endometrium, cervix and ovaries (Malla et al., 2015; Lv et al., 2017).

Activation of mTOR results in phosphorylation and change in the functional activity of S6K-protein kinase (p70S6K), which is responsible for protein synthesis in ribosomes and regulates growth, proliferation, apoptosis, cell survival, as well as metastasis and invasion of cancer cells. Phospho-p70S6K also affects the insulin receptor and enhances the state of insulin resistance. Today the ability of p70S6K to activate estrogen receptors in cells of mammary glands is known (Holz, 2012; Karlsson et al., 2015).

Thus, numerous studies prove the negative influence of pathogenetic factors of T2D on the functioning of intracellular systems of regulation of metabolic processes and recovery. Phosphorylated PRAS40 (phospho-PRAS40) and p70S6K (phospho-p70S6K) can be important for early recognition of oncogenic processes in patients with T2D.

As peripheral blood mononuclear cells (PBMCs), lymphocytes and macrophages involved in the pathogenesis of diabetes and cancer, the activity of protein kinases in these cells may reflect the activation of oncogenesis by both diseases.

The aim of the study was to investigate the activation of $\mathrm{P} I 3 \mathrm{~K} / \mathrm{AkT} / \mathrm{mTOR}$ in women with T2D and breast and endometrial cancer by studying PRAS40 and p70S6K1 phosphorylation and to examine its link with pathogenetic factors of T2D.

\section{Materials and methods}

The clinical trial was carried out in accordance with the guidelines of the Helsinki Declaration (1975). All patients signed an informed consent for further diagnostic and research work. During the study 65 women were examined. Patients were divided into groups: I - healthy (control group, $\mathrm{n}=10)$, II - women with T2D $(\mathrm{n}=15)$, III - women with breast and endometrial cancer without T2D $(n=20), I V-$ women with combination of cancer and T2D $(n=20)$. Patients were grouped according to age and BMI.

Therapy for patients with DM in groups II and IV included various combinations of hypoglycemic pills and insulin. Patients with cancer were those who were proven to have malignant tumours and who were prescribed antitumour treatment. Blood collection was carried out before the chemotherapy or hormonal therapy.

The content of PRAS40 [pT246] was determined in PBMCs using the ELISA kit KHO0421 Invitrogen company (USA), content of p70S6K1 (Total/ Phospho) - using the ELISA kit 85-86053 Invitrogen company (USA). Immediately after collection, blood was centrifuged using Histopaque 1077 Sigma (USA). The obtained white blood cells were washed and frozen at $-80^{\circ} \mathrm{C}$ before use. The cells were lysed in a buffer for extraction using a kit containing protease and phosphatase inhibitors. Studies were conducted in triplets. The concentration of protein in lysate was determined using the Novagen kit "BCA protein assay kit" (USA). Measurements were carried out with a microplate reader of the company "Bio-tek Instruments" (USA) at a wavelength of $450 \mathrm{~nm}$. Insulin and IGF-1 levels were determined using the automatic analyzer Stat fax 303+ (USA) using diagnostic kits Insulin ELISA, EIA-2935 and IGF-1 600 ELISA, EIA-4140 DRG company (Germany). DM compensation was assessed by determining the level of HbAlc by the method of ion-exchange chromatography, using the BIO-RAD D10 analyzer, the BIO-RAD (USA) reagents. PRAS40, insulin, IGF-1 and $\mathrm{HbAlc}$ levels were determined in units, according to the study guide; the level of p70S6K1 was determined in conventional units, depending on the amount of protein in the blood cell lysates, according to the protocol of the study.
Analysis of the data was carried out using Statistica 12.0 (StatSoft Inc., USA) program. The data are presented in the tables as $\mathrm{x} \pm \mathrm{SD}(\mathrm{x} \pm$ standard deviation). Differences between the values in the control and experimental groups were determined using the Tukey test, where the differences were considered reliable at $\mathrm{P}<0.05$ and $\mathrm{P}<0.001$ (taking into account the Bonferroni Correction).

\section{Results}

It has been found that breast and endometrial cancer occur in postmenopausal women with T2D on the background of obesity. The average age of the women in group IV, in whom cancer appeared on a background of T2D, was in the range 59-77 and duration of diabetes up to 10 years (Table 1$)$.

Table 1

Characteristics of age, BMI and duration

of DM of patients involved in the study $(\mathrm{x} \pm \mathrm{SD})$

\begin{tabular}{lcccc}
\hline \multicolumn{1}{c}{ Indexes } & $\begin{array}{c}\text { Group I, } \\
\text { control group, } \\
\mathrm{n}=10\end{array}$ & $\begin{array}{c}\text { Group II, } \\
\mathrm{T} 2 \mathrm{D}, \\
\mathrm{n}=15\end{array}$ & $\begin{array}{c}\text { Group III, } \\
\text { Cancer, } \\
\mathrm{n}=20\end{array}$ & $\begin{array}{c}\text { Group IV, } \\
\text { T2D with } \\
\text { cancer, } \mathrm{n}=20\end{array}$ \\
\hline Age, years & $58.9 \pm 8.9^{\mathrm{a}}$ & $55.8 \pm 5.8^{\mathrm{a}}$ & $61.7 \pm 8.1^{\mathrm{a}}$ & $62.2 \pm 6.7^{\mathrm{a}}$ \\
BMI, $\mathrm{kg} / \mathrm{m}^{2}$ & $29.2 \pm 3.8^{\mathrm{a}}$ & $31.9 \pm 3.3^{\mathrm{a}}$ & $32.7 \pm 3.5^{\mathrm{a}}$ & $30.9 \pm 5.3^{\mathrm{a}}$ \\
Duration ofDM, years & $-{ }^{\#}$ & $10.6 \pm 8.9^{\mathrm{a}}$ & $-{ }^{\#}$ & $6.0 \pm 3.7^{\mathrm{b}}$ \\
\hline
\end{tabular}

Note: different letters indicate values which reliably differed one from another within one line of the table according to the results of comparison using the Tukey test with Bonferroni Correction, ${ }^{\#}$ - duration of DM for women without diabetes was not determined.

According to the results, by the level of HbAlc, $33.3 \%$ of patients in group II with T2D had compensated DM, 13.3\% - subcompensated, $53.3 \%$ - decompensated (Fig. 1).

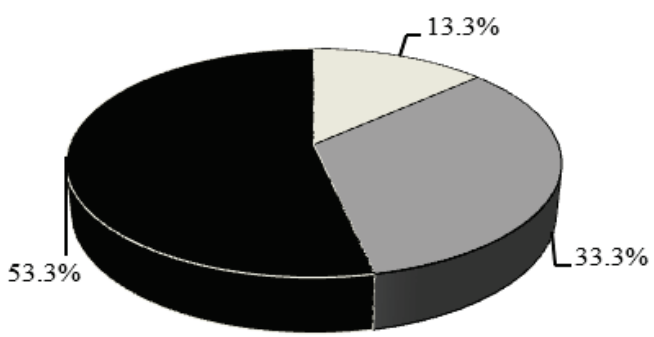

Fig. 1. Compensation of diabetes in women of group II with T2D: white - compensated DM ( $\mathrm{HbAl} 1 \mathrm{c}<7.0 \%)$; grey-subcompensated $\mathrm{DM}$ (HbA1c 7.0-7.5\%); black - decompensated DM (HbA1c > 7.5\%)

In patients in group IV, who had T2D with cancer, compensated diabetes was detected in $5.0 \%$ of patients, subcompensated - in $20.0 \%$, decompensated - in $75.0 \%$ (Fig. 2).

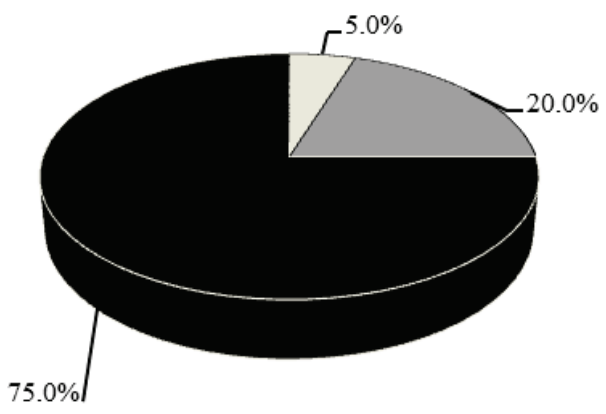

Fig. 2. Compensation of DM in women with combination of T2D and cancer of group IV: white - compensated DM ( $\mathrm{HbAlc}<7.0 \%)$; grey - subcompensated DM (HbAlc 7.0-7.5\%);

black - decompensated DM (HbAlc $>7.5 \%)$

According to the results of immune-enzymatic analysis, significant hyperinsulinemia, compared to the control group, was detected in patients of group II with T2D $(\mathrm{P}<0.001)$ and in patients of group IV with combination T2D and cancer $(\mathrm{P}<0.05)$. The level of insulin in patients of group II was significantly higher than in patients with cancer of group 
III $(\mathrm{P}<0.001)$ and in patients with combination T2D and cancer of group IV $(\mathrm{P}<0.05)$. The level of insulin in patients with cancer without DM of group III was significantly lower than in both groups with T2D: II group $(\mathrm{P}<0.001)$ and IV group $(\mathrm{P}<0.05)$. A significantly higher level of IGF-1, compared to other groups $(\mathrm{P}<0.001)$, was found only in patients with cancer of group III. Women with T2D of group II had significantly higher levels of phospho-PRAS40 in comparison to the control group and to group IV of patients with combination of T2D and cancer $(\mathrm{P}<0.001)$. Higher levels of phospho-PRAS40 were also found in patients with cancer without DM of group III, in comparison to the control group $(\mathrm{P}<0.05)$ and in comparison to group IV $(\mathrm{P}<0.001)$. In patients with a combination of both diseases, T2D and cancer, level of phospho-PRAS40 was significantly lower than in the control group $(\mathrm{P}<0.001)$ (Table 2).

The level of phospho-p70S6K1 in patients of group II with T2D was significantly higher than in patients of the control group and of IV group $(\mathrm{P}<0.05)$. Patients with cancer without $\mathrm{DM}$ of group III also had a significantly higher level of phospho-p70S6K1 compared to the control group and to the IV group $(\mathrm{P}<0.05)$ (Table 2$)$.

Table 2

The level of insulin, IGF-1, phospho-PRAS40

and phospho-p70S6K in women with type $2 \mathrm{DM}$ and cancer $(\mathrm{x} \pm \mathrm{SD})$

\begin{tabular}{lcccc}
\hline \multirow{1}{c}{ Groups } & $\begin{array}{c}\text { Group I, } \\
\text { control } \\
\text { group }\end{array}$ & $\begin{array}{c}\text { Group II, } \\
\text { T2D } \\
\mathrm{n}=10\end{array}$ & $\begin{array}{c}\text { Group III, } \\
\text { cancer } \\
\end{array}$ & $\begin{array}{c}\text { Group IV, } \\
\text { T2D with } \\
\text { cancer } \\
\mathrm{n}=20\end{array}$ \\
\hline Insulin, $\mathrm{mcIU} / \mathrm{mL}$ & $7.1 \pm 2.4^{\mathrm{a}}$ & $25.2 \pm 10.7^{\mathrm{b}}$ & $11.0 \pm 2.1^{\mathrm{a}}$ & $17.5 \pm 9.6^{\mathrm{b}}$ \\
IGF-1, ng/mL & $141 \pm 29^{\mathrm{a}}$ & $177 \pm 27^{\mathrm{a}}$ & $384 \pm 26^{\mathrm{b}}$ & $182 \pm 30^{\mathrm{a}}$ \\
Phospho-PRAS40, & $1.15 \pm$ & $1.72 \pm$ & $1.66 \pm$ & $0.13 \pm$ \\
unit/mL & $0.10^{\mathrm{a}}$ & $0.41^{\mathrm{b}}$ & $0.50^{\mathrm{b}}$ & $0.01^{\mathrm{c}}$ \\
Phospho-p70S6K, & $0.011 \pm$ & $0.017 \pm$ & $0.016 \pm$ & $0.010 \pm$ \\
(conv. units/mg prot.) & $0.003^{\mathrm{a}}$ & $0.009^{\mathrm{b}}$ & $0.001^{\mathrm{b}}$ & $0.002^{\mathrm{a}}$ \\
\hline
\end{tabular}

Note: different letters indicate values which reliably differed one from another within one line of table according to the results of comparison using the Tukey test with Bonferroni correction.

In the course of the research, the following correlations were found between the investigated indicators. In women of group II with T2D phospho-PRAS40 correlates with insulin $(\mathrm{r}=0.724, \mathrm{P}<0.001)$, IGF-1 $(\mathrm{r}=0.669, \mathrm{P}<0.001), \mathrm{HbA1c}(\mathrm{r}=0.597, \mathrm{P}<0.01)$ and phosphop70S6K $(r=0.530, P<0.05)$. Reliable correlation also was found in this group between HbAlc and IGF-1 $(r=0.609, \mathrm{P}<0.001)$. In women with cancer of group III phospho-PRAS40 correlates with BMI $(\mathrm{r}=$ $0.518, \mathrm{P}<0.05$ ) and in women with combination of T2D and cancer of group IV phospho-PRAS40 also correlates with BMI $(\mathrm{r}=0.538, \mathrm{P}<$ 0.05) (Fig. 3).

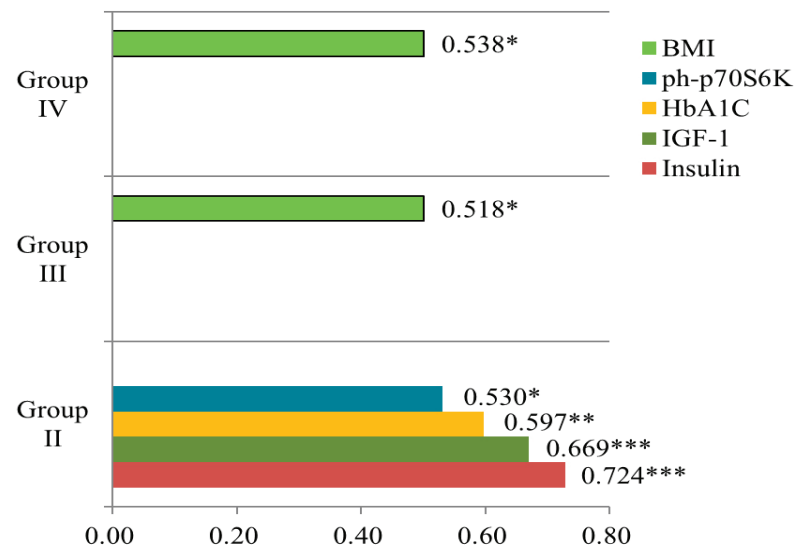

Fig. 3. Correlation links of phospho-PRAS40 in different groups: ${ }^{*}-\mathrm{P}<0.02,{ }^{* *}-\mathrm{P}<0.01, * * *-\mathrm{P}<0.001$

Phospho-p70S6K1 in women with T2D of group II correlates with IGF-1 $(r=0.864, \mathrm{P}<0.001), \mathrm{HbA1} \mathrm{c}(\mathrm{r}=0.618, \mathrm{P}<0.001)$ and phosphoPRAS40 ( $\mathrm{r}=0.530, \mathrm{P}<0.05)$; in women with combination of T2D and cancer of group IV correlative links with phospho-p70S6K1 were not found.

\section{Discussion}

The results confirm the frequent clinical cases of breast and endometrial cancer in postmenopausal women on the background of obesity. The cancer mechanism of these localizations is closely related to obesity and is based on the ability of the adipose tissue, namely in the mammary gland, to synthesize estrogens by activating peripheral aromatisation of androgens and by reducing the level of sex hormone binding globulin (SHBG) (Simo et al., 2015; Blakemore \& Naftolin, 2016; Onstad et al., 2016).

By normal body weight, only $1 \%$ of androstendione is converted into estrone, but with obesity this figure is 10 times higher. In the postmenopausal period in obese women the peripheral synthesis of estrogens in the adipose tissue is overwhelming. Hyperestrogenism stimulates the local synthesis of IGF-1 in the tissues of the glandular organs. The increased risk for obese women to have primary multiple malignant tumours with a combination of endometrial, breast, ovary and colon cancer has been proved (Vicennati et al., 2015). In women with T2D, obesity is considered as a risk factor for postmenopausal breast, endometrial and ovarian cancer (Nagle et al., 2016).

According to our results, cancer occurs in patients with type T2D with a relatively short duration of illness (up to 10 years), which also confirms the influence of hyperinsulinemia on the pathogenesis of cancer of this localization (Table 1, 2). In addition, the HbAlc level indicates the associated negative effect of both diseases, since hyperglycemia promotes cancer and cancer contributes to decompensation of diabetes. It is known that hyperglycemia through oxidative stress and accumulation of ROS causes the oxidation of important cellular components, including DNA, causing mutational effects through mytogen-activated protein kinase (MAPK).

Increased levels of insulin in patients of groups II and IV with T2D confirm that they have the condition of insulin resistance. According to our results, significant increase of IGF-1 in patients with diabetes of group II was not found, but in other scientific studies an increase of IGF-1, which was caused by the hyperinsulinaemia, has been shown (Dai et al., 2016). In addition, there is evidence of increased levels of another growth factor in patients with T2D, IGF-2, which competitively binds to IGF-1 receptor (IGF-1R), which increases bioavailability of IGF-1 and promotes the development of endometrial cancer (Xin et al., 2015).

High levels of insulin and IGF-1 in women with cancer of group III may be attributed to the effect of obesity and pro-inflammatory cytokines on the insulin sensitive cells (Dossus et al., 2010). Excessive production of TNF- $\alpha$ leads to the excessive activity of cyclooxygenase- 2 (COX-2) and to overproduction of prostaglandins (PG), which contribute to synthesis of IGF-1, epidermal growth factor (EGF) and vascular endothelial growth factor (VEGF). IL-6 also activates PI3/Akt/mTOR signal path. The influence of the cytokine imbalance on the development of endometrial and breast cancer was proved (Friedenreich et al., 2012; Gelsomino et al., 2019). In addition, local proliferative effects of high concentrations of insulin and IGF-1 in the tissues of glandular organs in postmenopausal women have been established. With endometrial cancer, insulin and estrogens have synergistic effects for the development and progression of oncological processes (Tian et al., 2017).

Increased levels of phospho-PRAS40 and phospho-p70S6K1 in women with diabetes of group II confirm the influence of pathogenetic factors of T2D, such as obesity, cytokine imbalance, hyperinsulinemia and hyperglycemia, on the systems of regulation of cell proliferation, survival and apoptosis. As is shown in Figure 4, insulin and IGF-1 are the main factors of stimulation of these systems. These growth factors stimulate PI3K and PI3K-related protein kinases Akt and mTOR through insulin receptor's substrate (IRS). PRAS40 is a substrate of Akt in the mTORC1 complex. Phosphorylation of PRAS40 regulates mTOR activity. Ribosomal protein S6 kinase (p70S6K) also takes part in the activation of PI3K-pathway and regulates protein synthesis at ribosomes. Activation of $\mathrm{p} 70 \mathrm{~S} 6 \mathrm{~K}$ leads to the increase of protein synthesis and cell proliferation. On the other hand, insulin and IGF-1 can influence the processes of proliferation and apoptosis through the RAS/RAF/MAPK pathway (Fig. 4). Thus, women of group II with T2D had multiple factors for activation of the different signalling pathways. Phosphorylation 
of protein kinases PRAS40 and p70S6K1 reflects the activation of one of the most important PI3/Akt/mTOR pathways, which is involved in the pathogenesis of cancer. In this group, women with obesity, hyperglycemia and hyperinsulinemia have significant predisposition to cancer. The increased levels of phosphorelated PRAS40 and p70S6K1 in patients with cancer of group III confirm the common mechanisms of activation of $\mathrm{PI} 3 \mathrm{~K} / \mathrm{Akt} / \mathrm{mTOR}$ pathway by T2D and cancer. According to our results, patients of this group have hyperinsulinemia, but it is not significant $(\mathrm{P}>0.05)$. In other studies, hyperinsulinemia is defined as an important prognostic indicator of the efficacy of treating women with nondiabetic breast cancer and regardless of menopausal status, stage of disease, expression and sensitivity of cellular receptors to hormones and to the epidermal growth factor (Ferroni et al., 2016). Results of another analysis showed, that hyperinsulinemia increases the risk of endometrial cancer even regardless of BMI (Nead et al., 2015). The results obtained in patients in group III confirm the main role of IGF-1 in activating the $\mathrm{PI} 3 \mathrm{~K} / \mathrm{Akt} / \mathrm{mTOR}$ pathway, which coincides with conclusions of other studies (Misnikova, 2016).

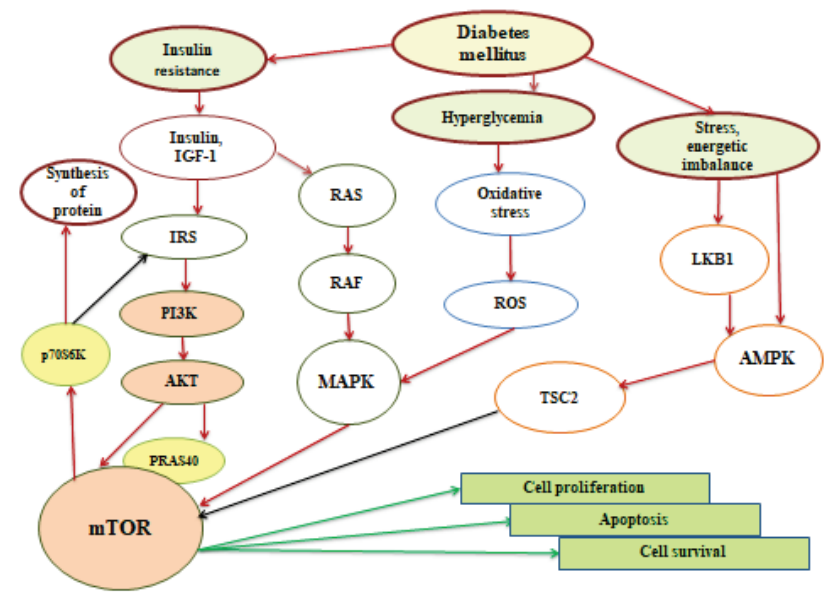

Fig. 4. Mechanisms of activation of oncogenesis in patients with T2D: IGF-1 - insulin-like growth factor; IRS - insulin receptor's substrate; PI3K - phosphatidylinositol 3-kinase; Akt - alpha serine/threonineprotein kinase B; PRAS40 - proline-rich Akt substrate of 40kDa; mTOR - mammalian target of rapamycin; p70S6K - ribosomal protein S6 kinase; RAS - membrane-bound proteins, which are involved in signal transduction; RAF - proteins, components of MAPK kinase; MAPK - mitogen-activated protein kinase; ROS -reactive oxygen species; LKB1 - liver kinase B1; AMPK - adenosine monophosphateactivated protein kinase; TSC2 - tuberous sclerosis complex 2; $\rightarrow-$ stimulation; $\rightarrow-$ inhibition; $\rightarrow-$ regulation

The activation of PI3K/Akt/mTOR pathway in women of group III by phosphorylation of PRAS40 and p70S6K1 can be caused by hormonal imbalance with hyperestrogenism, which is typical for endometrial and breast cancer. The physiological effect of estrogen is realized through two subtypes of receptors to estrogen (ER) - ER $\alpha$ and ER $\beta$. Hyperestrogenism and an elevation of ER $\alpha$ in the epithelium of mammary glands increase the mitogenic activity of cells and contribute to the development of breast cancer (in 75\% of cases) (Tian et al., 2017). There is evidence that mTORC1 and p70S6K directly phosphorylate and activate ER $\alpha$. On the other hand, the level of estrogen determines the expression of p70S6K. Direct relationship between mTORC1 and $\mathrm{ER} \alpha$ was revealed. By hyperestrogenism ER $\alpha$ binds to the regulatoryassociated protein mTOR (raptor), causes its translocation to the nucleus and activates the transcription of the target genes of ER. The results of scientific research prove that activation of the $\mathrm{mTORC} 1 / \mathrm{p} 70 \mathrm{~S} 6 \mathrm{~K}$ signalling is closely related to ER-positive breast and endometrial cancer and can be used as a diagnostic and prognostic marker (Holz, 2012; Alayev et al., 2015).

An unexpected result was the reduction of phospho-PRAS40 and phospho-p70S6K in patients with combination of T2D and cancer, regardless of the high levels of insulin in this group. This effect can be explained by the inhibition of mTOR by the liver kinase B1 (LKB1) and adenosine monophosphate-activated protein kinase (AMPK), which are activated due to severe energy deficiency and metabolic stress. AMPK activates the tuberous sclerosis complex 2 (TSC2) through its phosphorylation and leads to the inhibition of $\mathrm{mTORC1}$ signalling also via phospho-PRAS40 (Li et al., 2015; Wang, 2016; Zhang et al., 2017) (Fig. 4). In addition, the obtained results may be related to the influence of hypoglycemic drugs, in particular, insulin and metformin, which have different effects on the activity of regulatory systems. Another explanation may be the competitive interaction of signaling pathways at the substrates level, as hyperinsulinemia activates not only PI3K/Akt/mTOR but also the RAS/RAF/MAPK signalling pathway that can affect the mTORC by phosphorylation TSC2 and PRAS40 (Kim et al., 2017) (Fig. 4). These issues require further study.

The data obtained through correlation analysis confirm the role of insulin, IGF-1 and hyperglycemia in activating the PI3K/Akt/mTOR signalling pathway by T2D. Obesity is an important factor of cancerogenesis in women in the menopausal period and with T2D as well.

Thus, the results of this research confirm the influence of pathogenetic factors of T2D on the activation of intracellular regulatory systems. The functioning of these systems depends on the ratio of factors which activate and inhibit them. Obese women who have insulin resistance with decompensated T2D have significant prerequisites for the development of breast and endometrial cancer in menopausal period.

The practical value of determining the levels of insulin, IGF-1, phospho-PRAS40 and phospho-p70S6K1 lies in the early diagnosis of dysregulation and dysfunction of PI3/Akt/mTOR pathway, which is one of the most important in controlling the processes of apoptosis, survival and proliferation of cells. Increased levels of phospho-PRAS40 and phospho-p70S6K1 in healthy women and in women with T2D on the background of obesity can be an indication for additional examination.

\section{Conclusions}

The results of the study confirm the activation of the signalling pathway P13K/Akt/mTOR in women with T2D under the influence of pathogenetic factors such as hyperinsulinemia, hyperglycemia and obesity. The phosphorylation of PRAS40 and p70S6K1 reflects the activation of the signalling path. Increased levels the phospho-PRAS40 and phospho-p70S6K1 can be considered as early markers of oncogenesis activation in women with T2D and as an additional indication for screening for endometrial and breast cancer. In the future, it is planned to study the influence of various groups of hypoglycemic medications on the path $\mathrm{P} 13 \mathrm{~K} / \mathrm{Akt} / \mathrm{mTOR}$.

\section{References}

Alayev, A., Salamon, R. S., Berger, S. M., Schwartz, N. S., Cuesta, R., Snyder, R. B., \& Holz, M. K. (2016). mTORC1 directly phosphorylates and activates ER $\alpha$ upon estrogen stimulation. Oncogene, 35(27), 3535-3543.

Beg, M. S., Dwivedi, A. K., Ahmad, S. A., Ali, S., \& Olowokure, O. (2014). Impact of diabetes mellitus on the outcome of pancreatic cancer. Plos One, 9(5), e98511.

Blakemore, J., \& Naftolin, F. (2016). Aromatase: Contributions to physiology and disease in women and men. Physiology, 31, 258-269.

Chang, S.-C., \& Yang, W.-C. V. (2016). Hyperglycemia, tumorigenesis, and chronic inflammation. Critical reviews in oncology. Hematology, 108, 146-153.

Chen, J., Zhao, K. N., Li, R., Shao, R., \& Chen, C. (2014). Activation of $\mathrm{PI}_{3} \mathrm{~K} / \mathrm{Akt} / \mathrm{mTOR}$ pathway and dual inhibitors of $\mathrm{PI}_{3} \mathrm{~K}$ and $\mathrm{mTOR}$ in endometrial cancer. Current Medicinal Chemistry, 21(26), 3070-3080.

Dai, C., Li, N., Song, G., Yang, Y., \& Ning, X. (2016). Insulin-like growth factor 1 regulates growth of endometrial carcinoma through $\mathrm{PI}_{3} \mathrm{k}$ signaling pathway in insulin-resistant type 2 diabetes. American Journal of Translational Research, 8(8), 3329-3336.

Dossus, L., Rinaldi, S., Becker, S., Lukanova, A., Tjonneland, A., Olsen, A., Stegger, J., Overvad, K., Chabbert-Buffet, N., Jimenez-Corona, A., Clavel-Chapelon, F., Rohrmann, S., Teucher, B., Boeing, H., Schütze, M., Trichopoulou, A., Benetou, V., Lagiou, P., Palli, D., Berrino, F., Panico, S., Tumino, R., Sacerdote, C., Redondo, M. L., Travier, N., Sanchez, M. J., Altzibar, J. M., Chirlaque, M. D., Ardanaz, E., Bueno-de-Mesquita, H. B, van Duijnhoven, F. J., Onland-Moret, N. C., Peeters, P. H., Hallmans, G., Lundin, E., Khaw, K. T., Wareham, N., Allen, N., Key, T. J., Slimani, N., Hainaut, P., Roma- 
guera, D., Norat, T., Riboli, E., \& Kaaks, R. (2010). Obesity, inflammatory markers, and endometrial cancer risk: A prospective case-control study. Endocrine-Related Cancer, 17(4), 1007-1019.

Ferroni, P., Riondino, S., Laudisi, A., Portarena, I., Formica, V., Alessandroni, J. Alessandro, R., Orlandi, A., Costarelli, L., Cavaliere, F., Guadagni, F., \& Roselli, M. (2016). Pretreatment insulin levels as a prognostic factor for breast cancer progression. The Oncologist, 21(9), 1041-1049.

Friedenreich, C. M., Langley, A. R., Speidel, T. P., Lau, D. C., Courneya, K. S., Csizmadi, I., Magliocco, A. M., Yasui, Y., \& Cook, L. S. (2012). Casecontrol study of markers of insulin resistance and endometrial cancer risk. Endocrine-Related Cancer, 19(6), 785-792.

Gang, P. J., Mo, L., Lu, Y., Runqi, L., \& Xing, Z. (2015). Diabetes mellitus and the risk of prostate cancer: An update and cumulative meta-analysis. Endocrine Research, 40(1), 54-61.

García-Jiménez, C., Gutiérrez-Salmerón, M., Chocarro-Calvo, A., García-Martinez, J. M., Castaño, A., \& De la Vieja, A. (2016). From obesity to diabetes and cancer: Epidemiological links and role of therapies. British Journal of Cancer, 114(7), 716-722.

Gelsomino, L., Naimo, G. D., Catalano, S., Mauro, L., \& Andò, S. (2019). The emerging role of adiponectin in female malignancies. International Journal of Molecular Sciences, 20(9), 2127.

Gu, L., Cao, C., Fu, J., Li, Q., Li, D. H., \& Chen, M. Y. (2018). Serum adiponectin in breast cancer: A meta-analysis. Medicine, 97(29), e11433.

Guerrero-Zotano, A., Mayer, I. A., \& Arteaga, C. L. (2016). $\mathrm{PI}_{3} \mathrm{~K} / \mathrm{AKT} / \mathrm{mTOR}$ Role in breast cancer progression, drug resistance, and treatment. Cancer and Metastasis Reviews, 35(4), 515-524.

Harding, J. L., Shaw, J. E., Peeters, A., Cartensen, B., \& Magliano, D. J. (2015) Cancer risk among people with type 1 and type 2 diabetes: Disentangling true associations, detection bias, and reverse causation. Diabetes Care, 38(2), 264-270.

Hare, S. H., \& Harvey, A. J. (2017). mTOR function and therapeutic targeting in breast cancer. American Journal of Cancer Research, 7(3), 383-404.

Hendriks, S. H., Schrijnders, D., van Hateren, K. J., Groenier, K. H., Siesling, S., Maas, A., Bilo, H. J. G., Landman, G. W. D., \& Kleefstra, N. (2018). Association between body mass index and obesity-related cancer risk in men and women with type 2 diabetes in primary care in the Netherlands: A cohort study (Zodiac-56). BMJ Open, 8(1), e018859.

Holz, M. K. (2012). The role of $\mathrm{S}_{6} \mathrm{~K}_{1}$ in ER-positive breast cancer. Cell Cycle, 11(17), 3159-3165

Joung, K. H., Jeong, J. W., \& Ku, B. J. (2015). The association between type 2 diabetes mellitus and women cancer: The epidemiological evidences and putative mechanisms. Biomed Research International, 2015, 920618

Karlsson, E., Magić, I., Bostner, J., Dyrager, C., Lysholm, F., Hallbeck, A. L., Stål, O., \& Lundström, P. (2015). Revealing different roles of the mTORtargets $\mathrm{S}_{6} \mathrm{~K}_{1}$ and $\mathrm{S}_{6} \mathrm{~K}_{2}$ in breast cancer by expression profiling and structural analysis. Plos One, 10(12), e0145013.

Kim, L. C., Cook, R. S., \& Chen, J. (2017). $\mathrm{mTORC}_{1}$ and $\mathrm{mTORC}_{2}$ in cancer and the tumor microenvironment. Oncogene, 36(16), 2191-2201.

Li, W., Saud, S. M., Young, M. R., Chen, G., \& Hua, B. (2015). Targeting AMPK for cancer prevention and treatment. Oncotarget, 6(10), 7365-7378.

Lv, D., Guo, L., Zhang, T., \& Huang, L. (2017). PRAS 40 signaling in tumor Oncotarget, 8(40), 69076-69085.

Lykholat, T., Lykholat, O., \& Antonyuk, S. (2016). Immunohistochemical and biochemical analysis of mammary gland tumours of different age patients. Cytology and Genetics, 50(1), 32-41.
Malla, R., Ashby, C. R., Narayanan, N. K., Narayanan, B., Faridi, J. S., \& Tiwari, A. K. (2015). Proline-rich AKT substrate of $40-\mathrm{kDa}\left(\mathrm{PRAS}_{40}\right)$ in the pathophysiology of cancer. Biochemical and Biophysical Research Communications, 463(3), 161-166.

Misnikova, I. V. (2016). Diabet i rak [Diabetes and cancer]. Rosiyskyy Medychnyy Zhurnal, 20, 1346-1350 (in Russian).

Nagle, C. M., Crosbie, E. J., Brand, A., Obermair, A., Oehler, M. K, Quinn, M., Leung, Y., Spurdle, A. B., \& Webb, P. M. (2016). The association between diabetes, comorbidities, body mass index and all-cause and cause-specific mortality among women with endometrial cancer. Gynecologic Oncology, 150(1), 99-105.

Nead, K. T., Sharp, S. J., Thompson, D. J., Painter, J. N., Savage, D. B., Semple, R. K., Barker, A., Perry, J. R. B., Attia, J., Dunning, A. M., Easton D. F., Holliday, E., Lotta, L. A., O’Mara, T., McEvoy, M., Pharoah, P. D. P., Scott, R. J., Spurdle, A. B., Langenberg, C., Wareham, N. J., \& Scott, R. A. (2015). Evidence of a causal association between insulinemia and endometrial cancer: A Mendelian randomization analysis. Journal of the National Cancer Institute, 107(9), djv178

Onstad, M. A., Schmandt, R. E., \& Lu, K. H (2016). Addressing the role of obesity in endometrial cancer risk, prevention, and treatment. Journal of Clinical Oncology, 34(35), 4225-4230.

Pan, H., Deng, L. L., Cui, J. Q., Shi, L., Yang, Y. C., Luo, J. H., Qin, D., \& Wang, L. (2018). Association between serum leptin levels and breast cancer risk: An updated systematic review and meta-analysis. Medicine, 97(27), e11345.

Saxton, R. A., \& Sabatini, D. M. (2017). mTOR signaling in growth, metabolism, and disease. Cell, 168(6), 960-976.

Simó, R., Sáez-López, C., Barbosa-Desongles, A., Hernández, C., \& Selva, D. M. (2015). Novel insights in SHBG regulation and clinical implications. Trends Endocrinology and Metabolism, 26, 376-383.

Tian, W., Teng, F., Zhao, J., Gao, J., Gao, C., Sun, D., Liu, G., Zhang, Y., Yu, S., Zhang, W., Wang, Y., \& Xue, F. (2017). Estrogen and insulin synergistically promote type 1 in endometrial cancer progression. Cancer Biology and Therapy, 18(12), 1000-1010.

Vatseba, T. S., \& Sokolova, L. K. (2018). Patohenetychni mekhanizmy onkohenezu na tli tsukrovoho diabetu ta analiz onkolohichnoyi zakhvoryuvanosti khvorykh na tsukrovyy diabet $\mathrm{v}$ Karpats'komu rehioni [Pathogenetic mechanisms of oncogenesis on the background of diabetes mellitus and analysis of oncological morbidity of patients with diabetes mellitus in the Carpathian region]. Endokrynologia, 23(2), 128-137 (in Ukrainian).

Vicennati, V., Garelli, S., Rinaldi, E., Rosetti, S., Zavatta, G., Pagotto, U., \& Pasquali, R. (2015). Obesity-related proliferative diseases: The interaction between adipose tissue and estrogens in post-menopausal women. Hormone Molecular Biology and Clinical Investigation, 21, 75-87.

Wang, Z., Wang, N., Liu, P., \& Xie, X. (2016). AMPK and cancer. In: Cordero, M., \& Viollet, B. (Ed.). AMP-activated Protein Kinase. Springer Cham. Pp. 203-226.

Xin, C., Jing, D., Jie, T., Wu-Xia, L., Meng, Q., \& Ji-Yan, L. (2015). The expression difference of insulin-like growth factor 1 receptor in breast cancers with or without diabetes. Journal of Cancer Research and Therapeutics, 11(2), 295-299.

Zhang, J., Wang, Y., Liu, X., Dagda, R. K., \& Zhang, Y. (2017). How AMPK and PKA interplay to regulate mitochondrial function and survival in models of ischemia and diabetes. Oxidative Medicine and Cellular Longevity, 2017, 4353510.

Zhu, B., Wu, X., Wu, B., Pei, D., Zhang, L., \& Wei, L. (2017). The relationship between diabetes and colorectal cancer prognosis: A meta-analysis based on the cohort studies. PLoS One, 12(4), e0176068. 